\title{
Parâmetros físico-químicos e sensoriais na avaliação da qualidade da piramutaba (brachyplatystoma vaillantii, valenciennes, 1840) inteira estocada em gelo*
}

\section{Physicochemical and sensory parameter in the quality evaluation of the entire piramutaba (Brachyplatystoma vaillantii, Valenciennes, 1840) stored on ice}

\author{
Leony Soares Marinho, ${ }^{* *}$ Emília do Socorro Conceição de Lima Nunes, ${ }^{* *}$ Micheli da Silva Ferreira, ${ }^{* *}$ \\ Maria Lucia Guerra Monteiro, ${ }^{* *}$ Fernando Elias Rodrigues da Silva, ${ }^{* *}$ Eliane Teixeira Mársico, ${ }^{* *}$ Mônica Queiroz de Freitas ${ }^{\star * *}$
}

\begin{abstract}
Resumo
A piramutaba (Brachyplatystoma vaillantii) é um peixe dulcícola de grande importância econômica para o estado do Pará. Durante a captura, manipulação, transporte e comercialização como peixe fresco, diversos metabólitos decorrentes de eventos bioquímicos podem ser formados, acarretando a deterioração do peixe. Estes metabólito,s ao serem analisados, caracterizam analiticamente o frescor do pescado. Os atributos sensoriais são de extrema relevância para estimar o frescor. Devido à escassez de dados sobre a qualidade da piramutaba capturada no litoral do estado do Pará, o presente estudo teve como objetivo acompanhar as alterações físico-químicas da piramutaba inteira estocada em gelo $\left(0 \pm 1^{\circ} \mathrm{C}\right)$ por $0,4,7,10,14$ e 18 dias e correlacionar tais alterações com as características sensoriais de aparência e odor durante este período, utilizando um protocolo elaborado pelo Método de Índice de Qualidade (QIM) especificamente para a espécie de peixe estudada. A qualidade de 68 amostras de piramutaba foi avaliada com relação às características sensoriais, pH, Bases Voláteis Totais (BVT), trimetilamina (TMA), aminas biogênicas (histamina, putrescina e cadaverina), reação para amônia $\left(\mathrm{NH}_{3}\right)$ e gás sulfídrico $\left(\mathrm{H}_{2} \mathrm{~S}\right)$. Considerando os resultados de BVT, sugere-se o valor de $20,00 \mathrm{mgN} / 100 \mathrm{~g}$ como limite de aceitação para este parâmetro. A histamina foi detectada no $10^{\circ}$ dia e a putrescina a partir do $14^{\circ}$ dia de estocagem, $\mathrm{NH}_{3}$ foi positivo para todos os tempos estudados $\mathrm{H}_{2} \mathrm{~S}$ negativos até o fim do tempo de estocagem. Considerando o protocolo QIM e os resultados das análises físico-químicos, o prazo de validade comercial estipulado para piramutaba quando mantida sob temperaturas de refrigeração $\left(0 \pm 1^{\circ} \mathrm{C}\right)$ foi de 10 dias, sendo a avaliação sensorial eficiente na observação dos padrões de identidade e qualidade para peixe fresco, mantendo as características de qualidade. A determinação de $\mathrm{pH}$, as quantificações de BVT e TMA, as análises das aminas biogênicas, $\mathrm{NH}_{3}$ e $\mathrm{H}_{2} \mathrm{~S}$ não foram conclusivas para avaliar o frescor da carne da piramutaba por se tratar de um peixe de água doce.
\end{abstract}

Palavras-chave: aminas biogênicas, BVT, QIM, validade comercial.

\begin{abstract}
The piramutaba (Brachyplatystoma vaillantii) is a freshwater fish of great economic importance to the state of Pará during the capture, handling, transportation and marketing as fresh fish, several compounds are formed due to biochemical events that result in the deterioration of fish and can be used for physicochemical evaluation of fish freshness by means of analytical procedures. Moreover, the quality of fresh fish can be evaluated by sensory characteristics. Due to the paucity of data on the quality of piramutaba captured off the Para State's coast, this study aimed to track changes in physical-chemical of the whole piramutaba stored on ice $\left(0 \pm 1^{\circ} \mathrm{C}\right)$ for $0,4,7,10,14$ and 18 days and correlate these changes with the sensory qualities of appearance and odor during this period using a protocol Quality Index designed specifically for the studied fish species. The quality of 68 piramutaba samples was evaluated taking into consideration the sensory characteristics, $\mathrm{pH}$, total volatile bases (TVB), trimethylamine (TMA), biogenic amines (histamine, putrescine and cadaverine), reaction for ammonia $\left(\mathrm{NH}_{3}\right)$ and hydrogen sulfide $\left(\mathrm{H}_{2} \mathrm{~S}\right)$. According to the results obtained from BVT, we suggest the value of $20.00 \mathrm{mgN} / 100 \mathrm{~g}$ as acceptance limits for this parameter. Histamine was detected at day 10, and histamine and putrescine from the 14th day of storage, not exceeding the limits of Brazilian legislation. All test results were positive for $\mathrm{NH}_{3}$ and $\mathrm{H}_{2} \mathrm{~S}$ negative since the first day of storage. Considering the protocol MIQ and the results of the physicochemical tests, the expiry date stipulated for commercial piramutaba when kept under refrigeration temperatures $\left(0 \pm 1^{\circ} \mathrm{C}\right)$ was 10 days, the sensory evaluation effectively observing the patterns of identity and quality for fresh fish, as they maintained acceptable sensory characteristics. The determination of $\mathrm{pH}$, measurements of TVB and TMA, the analysis of biogenic amines, $\mathrm{NH}_{3}$ and $\mathrm{H}_{2} \mathrm{~S}$ were not conclusive to evaluate the freshness of meat piramutaba because it is a freshwater fish.
\end{abstract}

Keywords: biogenic amines, BVT, comercial validity, QIM.

*Recebido em 17 de fevereiro de 2014 e aceito em 17 de dezembro de 2014.

**Programa de Pós-graduação em Higiene Veterinária e Processamento Tecnológico de Produtos de Origem Animal. Faculdade de Veterinária. Universidade Federal Fluminense (UFF). Departamento de Tecnologia dos Alimentos - UFF. Rua Dr. Vital Brazil Filho, 64 - Santa Rosa - Niterói/RJ. CEP:24230-340

***Universidade Federal Fluminense - UFF. Departamento de Tecnologia de Alimentos - Faculdade de Veterinária, Rua Vital Brasil Filho, $n^{\circ} 64$, CEP: 24230-340, Niterói, Rio de Janeiro - RJ, Brasil.

Autor para correspondência: Mônica Queiroz de Freitas. E-mail: mqueiroz@vm.uff.br 


\section{Introdução}

A piramutaba (Brachyplatystoma vaillantii) é um bagre de água doce da família Pimelodidae encontrada, principalmente, na foz Amazônica, no baixo Amazonas e na baía de Marajó. Apresenta importância comercial regional, principalmente para o mercado internacional devido ao sabor agradável e bom rendimento industrial; é o peixe de água doce mais capturado do Brasil (Barthem, 2003).

Alguns fatores inerentes ao pescado e etapas pós captura contribuem para perda de qualidade como as condições de higiene, transporte e armazenamento, o $\mathrm{pH}$ próximo à neutralidade, $\mathrm{o}$ alto teor de nutrientes, a ação de enzimas autolíticas presentes nos tecidos e a alta atividade metabólica da microbiota presente (Soares; Vale; Junqueira, 1998; Abreu et al, 2008).

Os metabólitos formados no processo de perda de qualidade constituem ferramentas analíticas para avaliar o frescor. Considerando o fato de que não há padrões de qualidade específicos para peixes dulcícolas, é fundamental o estudo desses parâmetros aliados à avaliação sensorial para estimar a validade comercial dessa espécie (Baixas-Nogueras et al., 2002; Giannini, 2003).

Devido à escassez de estudos relacionados com a qualidade da piramutaba capturada no litoral do estado do Pará e à importância econômica que essa espécie representa para a região, o presente estudo objetivou verificar as alterações físico-químicas da piramutaba armazenada em gelo por 18 dias, acompanhada por avaliação das características sensoriais de aparência e odor durante este período, utilizando para tal o protocolo QIM elaborado especificamente para a espécie de peixe em questão.

\section{Material e métodos}

Foram utilizados 68 exemplares de piramutaba inteira, com comprimento médio de 48,28 $\pm 8,70 \mathrm{~cm}$ e peso médio de 1,05 $\pm 0,68 \mathrm{~kg}$, capturados através da pesca com rede por barcos de um entreposto de pescado localizado no município de Vigia de Nazaré-PA, nos meses de maio, junho, agosto de 2010 e janeiro de 2011. As amostras foram mantidas em gelo a temperatura controlada de $0 \pm 1^{\circ} \mathrm{C}$ e analisadas nos dias $0,4,7,10,14$ e 18 de estocagem.

A análise sensorial foi realizada no entreposto por uma equipe de julgadores previamente treinada, utilizando o Protocolo QIM elaborado exclusivamente para a avaliação da piramutaba, segundo metodologia descrita por Huss et al. (1997) e Olafsdóttir et al. (1997). Os julgadores observavam o aspecto geral (superfície do corpo, nadadeiras, rigidez e firmeza da carne), olhos (forma, córnea e pupila) e brânquias (odor, cor e forma). Cada atributo recebeu uma pontuação de 0 a 2, totalizando 20 pontos de deméritos.

Utilizaram-se 48 amostras para a realização das análises físico-químicas que incluíram BVT, TMA, histamina, cadaverina, putrescina, $\mathrm{pH}, \mathrm{NH}_{3}$ e $\mathrm{H}_{2} \mathrm{~S}$. A quantificação de BVT e TMA, e a determinação do $\mathrm{pH}$, amônia e $\mathrm{H}_{2} \mathrm{~S}$ seguiram a metodologia descrita no Métodos Físico-químicos para análise de Alimentos do Instituto Adolpho Lutz (BRASIL, 2005). Os teores de histamina, putrescina e cadaverina, foram determinados conforme método cromatográfico descrito por Schutz et al. (1976).

Os resultados obtidos pelas análises sensorial, BVT, TMA e $\mathrm{pH}$ foram avaliados estatisticamente através da análise de regressão linear em função do tempo de estocagem, utilizandose o Statistical Analyses Systems (SAS, 1985).

\section{Resultados e discussão}

Os resultados das análises físico-químicas estão dispostos na Tabela 1 e na Tabela 2.

Tabela 1: Valores médios dos teores de BVT, TMA e pH, e resultados analíticos de $\mathrm{NH}_{3}$ e $\mathrm{H}_{2} \mathrm{~S}$ em músculo de piramutaba (Brachyplatystoma vaillantii) oriundos de pesca comercial na cidade de Vigia de Nazaré$\mathrm{PA}$, em diferentes dias de estocagem a $0 \pm 1^{\circ} \mathrm{C}$

\begin{tabular}{cccccc}
\hline $\begin{array}{c}\text { Dias de } \\
\text { estocagem }\end{array}$ & BVT & TMA & $\mathbf{p H}$ & $\mathbf{N H}_{3}$ & $\mathbf{H}_{\mathbf{2}} \mathbf{S}$ \\
\hline 0 & 10,15 & 0,73 & 6,52 & Positivo & Negativo \\
4 & 10,83 & 0,87 & 6,56 & Positivo & Negativo \\
7 & 9,97 & 0,51 & 6,73 & Positivo & Negativo \\
10 & 13,00 & 0,39 & 6,76 & Positivo & Negativo \\
14 & 20,00 & 0,51 & 6,86 & Positivo & Negativo \\
18 & 26,60 & 0,67 & 6,92 & Positivo & Negativo \\
\hline
\end{tabular}

Os teores médios de BVT em todo o período de estocagem variaram de 10,15 a $26,60 \mathrm{mgN} / 100 \mathrm{~g}$ Tabela 1). A partir do $14^{\circ} \mathrm{dia}$ de estocagem os julgadores atribuíram valores compatíveis com a rejeição dos peixes e, para este dia, o valor para a produção de bases voláteis foi de $20 \mathrm{mg} \mathrm{N} / 100 \mathrm{~g}$. Considerando a ausência do OTMA nesta espécie, que seria o substrato para produção de parte relevante do conjunto das BVTs, pode-se inferir que este valor estabeleça um limite analítico para este parâmetro.

Haja vista que a avaliação química do pescado através da determinação de BVT, utilizada há aproximadamente um século, é considerado um método padrão para a realização da inspeção de peixes (Timm e Jorgensen, 2002), considerado um método não sensorial de vasta utilização na avaliação da qualidade do pescado fresco e congelado (Huss, 1995; Pereira e Tenuta-Filho, 2005), é fundamental a adequação de valores para espécies dulcícolas.

Ogawa e Maia (1999) classificaram a qualidade de peixes marinhos de acordo com os resultados de BVT como excelente estado de frescor (BVT = 5 a $10 \mathrm{mgN}-\mathrm{BVT} / 100 \mathrm{~g}$ ), peixes com frescor razoável (BVT= 15 a $25 \mathrm{mgN}-\mathrm{BVT} / 100 \mathrm{~g}$ ), peixes no inicio da putrefação (BVT = 30 a $40 \mathrm{mgN}-\mathrm{BVT} / 100 \mathrm{~g}$ ) e peixes bastante deteriorados (acima de $50 \mathrm{mgN}-\mathrm{BVT} / 100 \mathrm{~g}$ ). No estudo em questão, ainda que haja necessidade de estudos mais aprofundados e como se trata de peixe de água doce, sugerese o mesmo valor para peixe em bom estado de conservação; frescor razoável de 10 a $19,00 \mathrm{mgN} / 100 \mathrm{~g}$ e perda de qualidade a partir de 20,00 mgN/100g.

Apesar da análise de BVT ser de fácil realização, ContrerasGuzmán, (1994) e Huss (1998) descrevem que os resultados obtidos por tal procedimento só apresentaram aumentos consistentes quando o pescado estava próximo da rejeição, de modo que não seria adequado para prognosticar a validade comercial a partir de dados intermediários, porém, teriam utilidade como indicador do período máximo de comercialização.

Os resultados médios de TMA observados na tab. 1 foram baixos e não conclusivos. Pode-se inferir que esta espécie possua 
traços de OTMA, como acontece com tilápias, que são peixes dulcícolas, gerando, na degradação desta molécula, quantidades ínfimas de TMA.

Embora Fraser e Sumar (1998) tenham considerado que a determinação de TMA em peixes seja utilizada universalmente como um indicador de deterioração microbiana, Huss (1995) afirmou que a TMA não é um bom indicador de qualidade em pescado, pois não indica o estágio inicial da deterioração. Vários autores questionam a utilização deste parâmetro analítico para peixes de água doce (Beraquet e Lindo 1985; Contreras-Guzmán, 1994), corroborando com as considerações deste estudo.

A presença de amônia nas amostras pode ser explicada pelo fato desta substância ser originada tanto a partir da desaminação de aminoácidos livres, como a partir da degradação de nucleotídeos no pescado recém-capturado (Pereira e Tenuta-Filho, 2005; Contreras-Guzmnán, 1994). A desaminação é realizada principalmente pela glutamato desidrogenase, uma enzima mitocondrial posteriormente, a $\mathrm{NH}_{3}$ proveniente da degradação de outros compostos nitrogenados, a exemplo de aminoácidos, juntamente com a TMA, formada a partir do OTMA, passa a se fazer presente (Ogawa e Maia, 1999).

A análise da $\mathrm{NH}_{3}$, a base volátil mais representativa no processo degradativo, tem sido proposta como um índice químico de determinação para avaliação da qualidade dos produtos pesqueiros (Contreras-Guzmán, 1994), por ser um indicador de deterioração (Baixas-Nogueras et al., 2002), já que é o metabólito de menor peso molecular resultante da degradação proteica. A partir do rigor mortis, a $\mathrm{NH}_{3}$ gerada pela ação microbiana, somada aos traços endógenos, justifica um aumento significativo nos níveis de BVT após a $1^{\text {a }}$ semana de estocagem. Por esse motivo, Contreras-Guzmán (1994) relatou maior confiança na análise de BVT comparada à $\mathrm{NH}_{3}$. Este aumento das BVT foi evidenciado neste estudo e reforça os resultados obtidos para $\mathrm{NH}_{3}$.

Soares et al. (2013) em seu estudo da vida útil de filés de tilápiado-nilo (Oreochromis niloticus) sem pele, armazenados em gelo, observaram que o menor valor de $\mathrm{pH}$ encontrado foi de 5,9 e o maior de $7,11 \mathrm{e}$, que a partir do $15^{\circ}$ dia atingiu valores acima do permitido pela legislação, também coincidindo com o período de rejeição sensorial pelo QIM. Observaram, ainda, que os teores de BVT variaram de 5,58 a 31,55 mg N/100g

Não foi observada a produção de aminas biogênicas até o $7^{\circ}$ dia de estocagem (Tabela 2).

Tabela 2: Resultados referentes à produção de histamina,

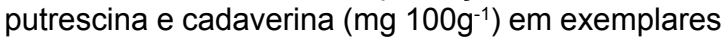
de piramutaba (Brachyplatystoma vaillantii) em diferentes dias de estocagem a $0 \pm 1^{\circ} \mathrm{C}$

\begin{tabular}{cccc}
\hline Dias de estocagem & $\begin{array}{c}\text { Histamina } \\
\left(\mathbf{m g 1 0 0 g}^{-1}\right)\end{array}$ & $\begin{array}{c}\text { Putrescina } \\
\left.\mathbf{( m g 1 0 0 g}^{-1}\right)\end{array}$ & $\begin{array}{c}\text { Cadaverina } \\
\left.\mathbf{( m g 1 0 0 g}^{-1}\right)\end{array}$ \\
\hline 0 & ND & ND & ND \\
4 & ND & ND & ND \\
7 & ND & ND & ND \\
10 & $<1$ & ND & ND \\
14 & $\sim 2$ & $<1$ & ND \\
18 & ND & $\sim 1$ & ND \\
\hline
\end{tabular}

ND: Não Detectado
O início da produção de histamina foi observado a partir do $10^{\circ} \mathrm{dia}$, com valor menor que $1 \mathrm{mg} / 100 \mathrm{~g}$. No $14^{\circ} \mathrm{dia}$, foram detectadas a histamina (semelhante a $2 \mathrm{mg} / 100 \mathrm{~g}$ ) e traços de putrescina $(<1 \mathrm{mg} / 100 \mathrm{~g})$. Histamina, putrescina e cadaverina, são metabólitos oriundos da descarboxilação de histidina, arginina e lisina por descarboxilases bacterianas.

Estimar a produção de aminas em pescado é essencial para avaliar a ação de enterobactérias e, consequentemente, a qualidade que, nas condições do presente estudo, pela manutenção controlada da temperatura, não constituíram fatores de risco, fato corroborado por Frazier e Westhoff (1993) quando relataram que o uso de baixa temperatura no pescado minimiza ou paralisa as atividades bacterianas no peixe, além de retardar reações químicas e a ação de enzimas de origem bacteriana que possuem a capacidade de descarboxilar certos aminoácidos. Huss (1995) descreveu que a única forma segura de prevenir a produção de histamina em peixes é através da correta utilização da cadeia de frio logo após a captura, especificamente a temperaturas inferiores a $4{ }^{\circ} \mathrm{C}$ até que este seja processado.

Embora alguns alimentos sejam naturalmente ricos em aminoácidos livres, o teor aumenta no período post mortem, devido à elevada atividade de enzimas proteolíticas presentes no trato intestinal do peixe (Flick e Granata, 2005; Saaid et al., 2009).

Contreras-Guzmán (1994) descrevem que algumas espécies de pescado apresentam baixas concentrações de histidina livre, incluindo nesse contexto, as trutas de água doce, camarões marinhos, peixes fermentados ou defumados e bagres, grupo do qual a piramutaba faz parte.

Na Tabela 3, estão apresentadas as equações de regressão dos valores de $\mathrm{pH}$ e de BVT das amostras estudadas. Esses dados demonstram que os valores de $\mathrm{pH}$ podem ser explicados em $95 \%$ no modelo proposto e os de BVT em $82 \%$, em função do tempo de estocagem. Tais resultados e o nível de significância demonstram uma evolução linear de tais parâmetros.

Tabela 3: Modelo de equação de regressão de pH e BVT em músculo de piramutaba (Brachyplatystoma vaillantii) em função do dia de estocagem (X) a $0 \pm 1{ }^{\circ} \mathrm{C}$ e respectivos valores de coeficiente de determinação $\left(R^{2}\right)$ e níveis de probabilidade

\begin{tabular}{cccc}
\hline Variável & Equação & $\mathbf{R}^{2}$ & Prob. > F \\
\hline $\mathrm{pH}$ & $\mathrm{Y}=6,511+0,024 . \mathrm{X}$ & 0,95 & 0,0007 \\
$\mathrm{BVT}$ & $\mathrm{Y}=6,860+0,932 . \mathrm{X}$ & 0,82 & 0,0130 \\
$\mathrm{TMA}$ & - & 0,17 & 0,4221 \\
\hline
\end{tabular}

Como observado na Tabela 3, os valores de TMA encontrados neste estudo não permitiram ajustar a equação de regressão em função da baixa variação deste parâmetro durante o período de estocagem. Isto significa que a análise de TMA não foi representativa para avaliar o frescor da piramutaba, fato já comentado anteriormente.

O valor médio de $\mathrm{pH}$ inicial foi de 6,52 no $1^{\circ}$ dia e, no $18^{\circ}$ dia de estocagem, 6,92 valor considerado alto quando se correlaciona ao limite preconizado pelo RIISPOA (Brasil, 1952), que prevê o valor inferior a 6,5. Ainda que os resultados tenham sido altos, 
as amostras apresentaram características sensoriais adequadas até $\mathrm{o} 10^{\circ}$ dia de estocagem.

Segundo Ogawa e Maia (1999), a determinação do pH não é um índice seguro para avaliar o estado de frescor ou estimar o início do processo degradativo; a utilização deste parâmetro é limitada pela vasta flutuação dos resultados em cada espécie estudada, tanto por questões endógenas quanto devido às etapas pós captura. No entanto, Love (1992) considerou o pH do músculo do pescado de grande importância tecnológica por ser o principal fator relacionado com a textura do músculo após cocção. Guimarães et al. (1988) verificaram que o pH de tilápias evisceradas no dia zero de estocagem foi de 6,9 , caindo para 6,0 no primeiro dia e subindo gradativamente, até alcançar 7,9 no $20^{\circ}$ dia de estocagem. Sales (1988) e Siqueira (2001), em estudos desenvolvidos em tilápia, observaram que desde o primeiro dia de estocagem os valores médios de $\mathrm{pH}$ encontravam-se fora dos limites, respectivamente, 6,7 e 6,6. Entretanto, Zúniga et al. (2005) encontraram o valor 6,9 , ou seja, superior ao permitido pela legislação somente a partir do $21^{\circ}$ dia de armazenamento.

Souza et al. (2013) evidenciaram em seus estudos com pescado congelado comercializado no Mercado Municipal de São Francisco do Conde-BA, que $62,7 \%$ das amostras analisadas estavam fora do limite permitido pela legislação para $\mathrm{pH}, 27,8 \%$ para BVT e $70,8 \%$ para gás sulfídrico. Em relação à prova de Éber para amônia, evidenciaram que $40,3 \%$ das amostras apresentaram-se positivas, estando em desacordo com recomendações técnicas.

Com relação aos diferentes resultados de $\mathrm{pH}$ obtidos, Huss (1998) descreveu que diversos fatores podem influenciar na glicólise post mortem e, consequentemente, no $\mathrm{pH}$, como a espécie, o estado nutricional, a quantidade e o grau de esgotamento do pescado no momento da morte.

$\mathrm{O}$ pH final da carne do pescado após sua morte está relacionado com a quantidade de glicogênio disponível. A diminuição é

\section{Referências}

ABREU, M. G.; FREITAS, M. Q.; JESUS, E. F. O.; SÃO CLEMENTE, S. C.; FRANCO, R. M.; BORGES, A. Caracterização sensorial e análise bacteriológica do peixe-sapo (Lophius gastrophtysus) refrigerado e irradiado. Revista Ciência Rural, v. 38, n. 2. Santa Maria, março/abril. 2008.

ASCAR, J. M. Alimentos: Aspectos bromatológicos e legais. São Leopoldo (RS): UNISINOS, 1985.

BAIXAS-NOGUERAS, S.; BOVER-CID, S.; VECIANA-NOGUÉS, M. T.; VIDALCAROU, M. C. Chemical and sensory changes in Mediterranean hake (Merluccius merluccius) under refrigeration $\left(6-8{ }^{\circ} \mathrm{C}\right)$ and stored ice. Journal of Agriculture and Food Chemistry, v. 50, p. 6504-6510, 2002.

BARTHEM, R. B. A Pesca e os recursos pesqueiros na Amazônia Brasileira. 2003. Disponível em: http://ns.rc.unesp.br/ib/ecologia/ petrere/text_os_arquivos/barthem2003.pdf. Acesso em: 09/11/2008.

BERAQUET, N. J.; LINDO, M. M. K. Transformações bioquímicas "post mortem" em pescado. Boletim do ITAL, v. 22, p. 169-192, 1985.

BRASIL. Ministério da Agricultura, Pecuária e Abastecimento. Decreto no 30.691 de 29 de março de 1952. Aprova o novo Regulamento da Inspeção Industrial e Sanitária de Produtos de Origem Animal - R.I.I.S.P.O.A. Departamento Nacional de Inspeção de Produtos de Origem Animal. Diário Oficial [da] República Federativa do Brasil, Brasília, DF, 1952. consequência da conversão do glicogênio em ácido lático (Frazier e Westhoff, 1993), levando em consideração que quando o peixe está vivo o pH muscular está próximo da neutralidade (Huss, 1998). Segundo Ascar (1985) a análise de $\mathrm{pH}$ é realizada para determinar a quantidade de ácidos que se encontra em um determinado alimento, visto que é um fator importante para a conservação do mesmo por limitar o crescimento de micro-organismos. Por esse motivo, as bactérias estimulam a produção de aminas como mecanismo de proteção (Silla-Santos, 1996).

Neste estudo os resultados analíticos para $\mathrm{H}_{2} \mathrm{~S}$ foram negativos em todas as amostras e em todos os tempos de estocagem. A legislação brasileira considera como deteriorado e, portanto, impróprio para consumo, o pescado com reação positiva para $\mathrm{H}_{2} \mathrm{~S}$ (Brasil, 2005). Hiluy et al. (2003) utilizaram a prova de $\mathrm{H}_{2} \mathrm{~S}$ como condenatória para peixes analisados em empresas pesqueiras de beneficiamento e no comércio varejista do município de Fortaleza, Brasil. Como neste estudo todo o período de estocagem foi mantido sob controle, pode-se afirmar que não houve falhas da cadeia de frio que pudessem propiciar a produção de $\mathrm{H}_{2} \mathrm{~S}$ pela atuação de bactérias mesofílicas.

\section{Conclusões}

Considerando os resultados dos parâmetros físico-químicos e os evidenciados no protocolo QIM, o prazo de validade comercial estipulado para piramutaba quando mantida sob temperaturas de refrigeração $\left(0 \pm 1^{\circ} \mathrm{C}\right)$ foi de 10 dias.

O valor de $20 \mathrm{mg} \mathrm{N} / 100 \mathrm{~g}$ para BVT foi estabelecido como limite de aceitação para piramutaba o que permite sugerir uma classificação para avaliar o estado de qualidade de peixes de água doce, como segue: peixes em bom estado de conservação (5 a 10 mg N/100g); com frescor razoável (10 a 19 mg N/100g) e com perda da qualidade (a partir de $20 \mathrm{mg} \mathrm{N} / 100 \mathrm{~g}$ ).

BRASIL. Ministério da Saúde. Agência Nacional de Vigilância Sanitária. Métodos Físico-químicos para análise de Alimentos/ Ministério da Saúde, Agência Nacional de Vigilância Sanitária. Brasília, DF: Ministério da Saúde, 2005.

BRESSAN, M. C.; PEREZ, J. R. O. Tecnologia de Carnes e Pescados. Lavras, 2000. 225 f: Especialização (Curso de Pós- Graduação "Lato Sensu" Especialização a Distância. Processamento e Controle de Qualidade em Carne, Leite, Ovos e Pescado). FAEPE, Universidade Federal de Lavras, Minas Gerais. 2000.

CONTRERAS-GUZMÁN, E. S. Bioquímica de pescado e derivados. Jaboticabal: FUNEP, 1994. p. 409.

FLICK, G. J.; GRANATA, L. A. Biogenic Amines in Foods. In: DABROWSKI, W. M.; SIKORSKI, Z. E. (Eds.). Toxins in Food. Chemical and Functional Properties of Food Components Series. CRC Press, 2005, p. 121-154.

FRASER, O. P.; SUMAR, S. Compositional changes and spoilage in fish (Parte II) microbiological induced deterioration. Nutrition and Food Service, n. 6, p. 325-329, nov-dez, 1998.

FRAZIER, W. C.; WESTHOFF, D. C. Microbiología de los alimentos. 4 ed. Zaragoza: Acribia, 1993. 681 p.

GIANNINI, D. H. Determinación de nitrógeno básico volátil (NBV) em pescado: consideraciones generales. Alimentaria, Madri, v. 40, n. 343, p. 49-54, 2003. 
GUIMARÃES O. J.; SALES, R. O.; MONTEIRO, J. C. S. Análise química, microbiológica e organoléptica da tilápia do Nilo (Sarotherodon nilotic), conservada em gelo. Revista Ciência Agronômica. v. 19, n. 1, p. 147-151, 1988.

HILUY, D. J.; FORTUNA, M. I.; ARAÚJO FERNABDES, A. R. Avaliação das condições higiênico-sanitárias da comercialização do pescado em Fortaleza - CE. In: XIII ENCONTRO NACIONAL DE ANALISTAS DE ALIMENTOS, v. 1, p. 259, 2003.

HUSS, H. H. Garantia da qualidade dos produtos da pesca. FAO - Organização das Nações Unidas para Agricultura e Alimentação - Documento técnico sobre as pescas 334. Roma, 1997, 176 p.

HUSS, H. H. El pescado fresco: su calidad y cambios de su calidad. FAO - Organização das Nações Unidas para Agricultura e Alimentação - Documento Técnico de Pesca 348. Roma, 1998. $202 \mathrm{p}$.

HUSS, H. H. Quality and quality changes in fresh fish: FAO: Fisheries Technical, Paper n. 348. Roma: Food and Agriculture Organization of the United Nations, 1995. 193 p.

LOVE, R. M. Biochemical dynamics and the quality of fresh and frozen fish. In: HALL, G. M. Fish processing technology Glasgow: Bleckie Academic e Professional, 1992. p. 1-31.

OGAWA, N. B. P.; MAIA, E.L. Manual de Pesca: ciência e tecnologia do pescado. São Paulo: Livraria Varela, 1999. 430 p.

OLAFSDÓTTIR, G.; MARTINSDÓTTIR, E.; OEHLENSCHLAGER, $P$. et al. Methods to determine the freshness of fish in research and industry. Proceedings of the Final Meeting of the Concerted Action "Evaluation of Fish Freshness". Nantes, 1997. International Institute of Refrigeration. p. 287-296. 396p.

PEREIRA, A. A. F.; TENUTA-FILHO, A. Avaliação de condições de consumo da sardinha (Sardinella brasiliensis). Ciência e Tecnologia de Alimentos, Campinas, v. 25, n. 4, p. 720-725, 2005.

SAAID, M.; SAAD, B.; HASHIM, N.H.; ALI A, S.M.; SALEH, M.I. Determination of biogenic amines in selected Malaysian food. Food Chemistry. v. 113, p. 1356-1362, 2009.

SALES, R.O. Avaliação do estado de frescor do pescado capturado em água doce e mantido sob refrigeração, no açude de Orós, Ceará. Revista Ciência Agronômica, v. 19, n. 2, p. 109-115, 1988.
SCHUTZ, D. E.; CHANG, G. W.; BJELDANES, L. F. Rapid thin layer chromatographic method for the detection of histamine in fish products. Journal of the AOAC. v. 59, n. 6, p. 1224 - 1225, 1976.

SILLA-SANTOS, M. H. Biogenic amines: their importance in foods. International Journal of Food Microbiology, v. 29, p. 213231, 1996.

SIQUEIRA, A. A. C. Z. Efeito da irradiação e refrigeração na qualidade e no valor nutritivo da tilápia (Oreochromis niloticus). Piracicaba, 2001. 154 f. Dissertação (Mestrado em Ciência e Tecnologia de Alimentos), Universidade de São Paulo, Piracicaba, 2001.

SOARES, K. M. P.; GONÇALVES, A. A. Aplicação do método do índice de qualidade (MIQ) para o estudo da vida útil de filés de tilápia-do-nilo (Oreochromis niloticus) sem pele, armazenados em gelo. Semina: Ciências Agrárias, Londrina. v. 33, n. 6, p. 22892300, nov./dez. 2012.

SOUZA, M. M. M.; FURTUNATO, D. M. N.; CARDOSO, R. C. V.; ARGÔLO, S. V.; SILVA, I. R. C. S.; SANTOS, L. F. P. Avaliação do frescor do pescado congelado comercializado no mercado municipal de São Francisco do Conde-BA. Boletim do Instituto de Pesca, São Paulo, v. 39, n. 4, p. 359-368, 2013.

SOARES, V. F. M.; VALE, S. R.; JUNQUEIRA, R. G. et al. Teores de histamina e qualidade físico-química e sensorial de filé de peixe congelado. Ciência e Tecnologia de Alimentos, v. 18, n. 4, p. 462-470, 1998.

STATISTICAL ANALYSES SYSTEMS (SAS). SAS ${ }^{\circledR}$ User's Guide. Carry: SAS Institute Inc. 1985, 959 p.

TIMM, M.; JORGENSEN, B. M. Simultaneous determination of ammonia, dimethylamine, trimethylamine and trimethylamineoxide in fish extracts by capillary electrophoresis with indirect UV-detection. Food Chemistry, Denmark, v. 76, n. 4, p. 509-518, 2002.

ZÚNIGA, N. O. C. et al. Determinação do prazo comercial da tilápia (Oreochromis niloticus) eviscerada e estocada temperatura de $0^{\circ} \mathrm{C}$ com base na contagem de bactérias aeróbias mesófilas e determinação de $\mathrm{pH}$. In: VIII CONGRESSO BRASILEIRO DE HIGIENISTAS DE ALIMENTOS, 2005. CD-ROM. 